\title{
DigiAtlas: Dispositivos Móveis Auxiliando o Ensino Multidisciplinar de Questões Ambientais
}

\author{
Lucas F. Ferreira ${ }^{1}$, Mrs. Mariana Raniero ${ }^{2}$, Dr. Gabriel G. Hornink ${ }^{2}$, \\ Dr. Paulo Alexandre Bressan ${ }^{1}$ \\ ${ }^{1}$ Laboratório de Tecnologia Educacional - Instituto de Ciências Exatas \\ Universidade Federal de Alfenas - Alfenas - MG - Brasil \\ ${ }^{2}$ Laboratório de Tecnologia Educacional - Instituto de Ciências Biológicas \\ Universidade Federal de Alfenas - Alfenas - MG - Brasil \\ lucasfaloni@bcc.unifal-mg.edu.br, m.raniero@hotmail.com, \\ paulo.bressan@gmail.com, gabrielbio@gmail.com
}

\begin{abstract}
Currently the environmental area is receiving greater attention. It is important for the understanding of our existence as part of a natural system and our responsibility under the same. This work presents the DigiAtlas application based on this theme, it features on a digital map, environment, abiotic and biotic data, and allows the management of these data. New data collected in the application can be shared, allowing the exchange of knowledge between users. The application was developed for mobile devices and can be used as a research tool, and teaching and learning in classrooms or field activities, including multidisciplinary way.
\end{abstract}

Resumo. Atualmente a temática ambiental está recebendo grande atenção devido a sua importância para o entendimento de nossa existência, como parte de um sistema natural e de nossa responsabilidade sob o mesmo. Este artigo apresenta o aplicativo DigiAtlas com base nessa temática, ele apresenta em um mapa digital dados ambientais, abióticos e bióticos, além de permitir o gerenciamento desses dados. Novos dados coletados na aplicação podem ser compartilhados permitindo a troca de conhecimento entre os usuários. $O$ aplicativo foi desenvolvido para dispositivos móveis e pode ser utilizado como ferramenta de pesquisa e de ensino-aprendizagem, em salas de aula ou atividades de campo, inclusive de maneira multidisciplinar.

\section{Introdução}

A temática ambiental se mostra complexa pela sua essência, já que o ambiente e os seres dependentes deste estão interligados através de complexos processos e relações. Com isso, a abordagem multidisciplinar de questões ambientais acaba por facilitar seu entendimento. A multidisciplinaridade torna-se necessária, já que o ambiente, e as importantes questões atuais, como a degradação e fragmentação das áreas nativas, o efeito estufa e as mudanças climáticas, são assuntos complexos que exigem o entendimento de várias disciplinas para sua compreensão. Além disso, essa abordagem pode trazer o interesse dos alunos, permitindo um olhar multifocal e dinâmico à aprendizagem e ao ensino [Duso \& Borges, 2010]. 


\section{CBIE-LACLO 2015}

Anais dos Workshops do IV Congresso Brasileiro de Informática na Educação (CBIE 2015)

A forma tradicional de ensino nas escolas têm cada vez mais dado espaço às dinâmicas de grupos e atividades externas devido à carência da atenção dos alunos. Nas últimas décadas a hiperatividade e o déficit na atenção, devido às mudanças na sociedade, tecnologia e comportamentos, têm aumentado [Crary, 1999].

Atividades como trabalhos de campo se encaixam nessa quebra de rotina da sala de aula. $\mathrm{O}$ trabalho de campo estimula a problematização e a inserção do aluno à sua realidade, e possibilita a capacidade criativa tanto do aluno como do professor ao desenvolver as atividades [Pinto, 2003].

Sharples e colaboradores [2007] apresentam uma nova ótica sobre o uso de dispositivos móveis no meio pedagógico, o mobile learning (“Aprendizado Móvel”). A abordagem tem como base as premissas de que o aprendizado e o aprendiz está em constante movimento, e a aprendizagem pode ocorrer em qualquer lugar e contexto. A tecnologia nos dispositivos móveis (tablets e smartphones) evolui rapidamente quando comparada à tecnologia de computadores pessoais, por exemplo. As funcionalidades que foram agregadas a dispositivos móveis, como wireless, serviço de localização, captura e exibição de mídias (áudio, foto e vídeo) entre outros, pode favorecer muito a utilização desses como ferramenta de ensino-aprendizagem. Além disso, a familiaridade dos alunos e o baixo custo desse tipo de tecnologia também justifica seu uso.

Este artigo apresenta na Seção 2 o referencial teórico para desenvolver aplicações educativas para dispositivos móveis. Na Seção 3 é apresentado o DigiAtlas, resultado da produção da aplicação proposta. Já a Seção 4 trata a análise dos resultados aplicados em um teste de usabilidade. Por último, são colocadas algumas considerações finais e perspectivas futuras para o trabalho na Seção 5.

\section{Referencial Teórico}

O avanço tecnológico da última década contribuiu com a disseminação em massa dos dispositivos móveis por todo o mundo, principalmente entre jovens, adolescentes e crianças que se encantam com maior facilidade pelos recursos disponíveis.

Os dispositivos móveis permitem acesso rápido a informações em qualquer local, inclusive no ambiente escolar. Embora muitos aplicativos desviem a atenção do aluno, diminuindo o interesse pelo processo ensino-aprendizado, os inúmeros recursos presentes nos dispositivos móveis (áudio, foto, vídeo, localizador geográfico, dentre outros), permitem a elaboração de formas diferentes de abordagem dos conteúdos curriculares. Assim, os professores têm a oportunidade de utilizar dispositivos móveis em sala de aula. Isto pode acontecer por meio da utilização de seus recursos por aplicativos básicos, de algum aplicativo já instalado no próprio dispositivo, ou através de aplicativos educacionais desenvolvidos para abordar disciplinas e conteúdos específicos.

No cenário brasileiro, a utilização de aplicativos educacionais cresce gradativamente, mas ainda são minoria. Segundo a empresa Distimo [2013], que faz análise de lojas de aplicativos, do total de aplicativos disponíveis em setembro de 2013, apenas 2\% na Google Play, loja virtual de aplicativos para Android, eram relacionados à educação. Além disso, muitos aplicativos educativos não abordam especificamente o 
conteúdo curricular escolar, ou abordam de maneira superficial e sem preocupações pedagógicas.

Portanto, o desenvolvimento de aplicativos que exerçam papel eficiente na educação e/ou na transferência de conhecimento pode favorecer o processo ensinoaprendizagem. Segundo Ferreira e Tomé (2010), os alunos tiveram maior interesse e facilidade com os currículos escolares, e assim alcançam maior fixação do conteúdo. A preocupação no desenvolvimento de aplicativos educacionais, a princípio, é o assunto a ser abordado, o conteúdo e as disciplinas a serem contempladas com as atividades, e quais tipos de atividades poderão ser desenvolvidas com o auxilio do aplicativo. Além disso, a experiência e mesmo a criatividade do professor quanto à essas atividades, também pode ser um entrave. Entretanto, o aproveitamento de um aplicativo de dispositivo móvel, que permita trabalhos de campo, soa positivo aos alunos que são sedentos por atividades dinâmicas e lúdicas. Finalmente, o interesse pela temática ambiental, com abordagem multidisciplinar torna a atividade e o aprendizado mais atraente.

\section{O DigiAtlas}

Neste projeto, foi desenvolvida uma aplicação de ensino-aprendizagem para dispositivos móveis que permite o gerenciamento de dados ambientais e ecológicos, e que podem ser trabalhados em várias etapas do ensino fundamental e médio, e ainda entre várias disciplinas. A aplicação disponibiliza uma base de dados com informações coletadas por pesquisadores e pós-graduandos da Universidade Federal de Alfenas (UNIFAL-MG) em projetos de iniciação científica, extensão e pós-graduação. Durante as atividades desenvolvidas pelos professores e alunos com o aplicativo, será possível inserir novos dados (imagens, sons, vídeos e textos).

A principal interação com os dados é através de um mapa, o que permite melhor noção de dispersão dos dados e melhor visualização da localidade de cada dado. A ferramenta permitirá após a adição de dados pelos usuários, o compartilhamento desses dados, contribuindo para a disseminação do conhecimento e incremento do próprio aplicativo.

O DigiAtlas foi elaborado para ser utilizado por dois perfis: Professor e Turma. O perfil Professor é fixo por ser o administrador do aplicativo, este pode criar ou apagar turmas. Cada perfil Turma tem permissão de edição e exclusão somente em dados adicionados pelo próprio perfil, assim como também visualizar somente as suas anotações, ou seja, comentários sobre uma determinada localidade.

Mostra-se na Figura 1 a interface após autenticação como Professor, com várias funcionalidades disponíveis para o usuário. No canto direito da barra superior existem as opções: Pesquisa, Informações, Ajuda, Configurações, Importar/Exportar e Enviar Dados para equipe DigiAtlas, essas três últimas disponíveis somente para Professor. Além disso, existem as funcionalidades "Ir para Mapa", "Criar Turma" e "Deletar Turma".

No aplicativo é apresentado o mapa disponibilizado pelo Google Maps onde foram adicionados marcadores nas localidades que possuem algum dado coletado. Uma localidade pode conter várias informações coletadas, por isso elas serão apresentadas 
após a seleção do marcador. Existem três tipos de marcadores, os que possuem somente dados validados (na cor verde), os que possuem somente dados não-validados (na cor vermelha) e os que possuem ambos (na cor amarela). Dados validados são aqueles que foram analisados e confirmados por pesquisadores/professores da UNIFAL-MG. Dados não-validados são aqueles inseridos pelos próprios usuários. A base de dados atual e as disponibilizadas por atualizações já estarão validadas.

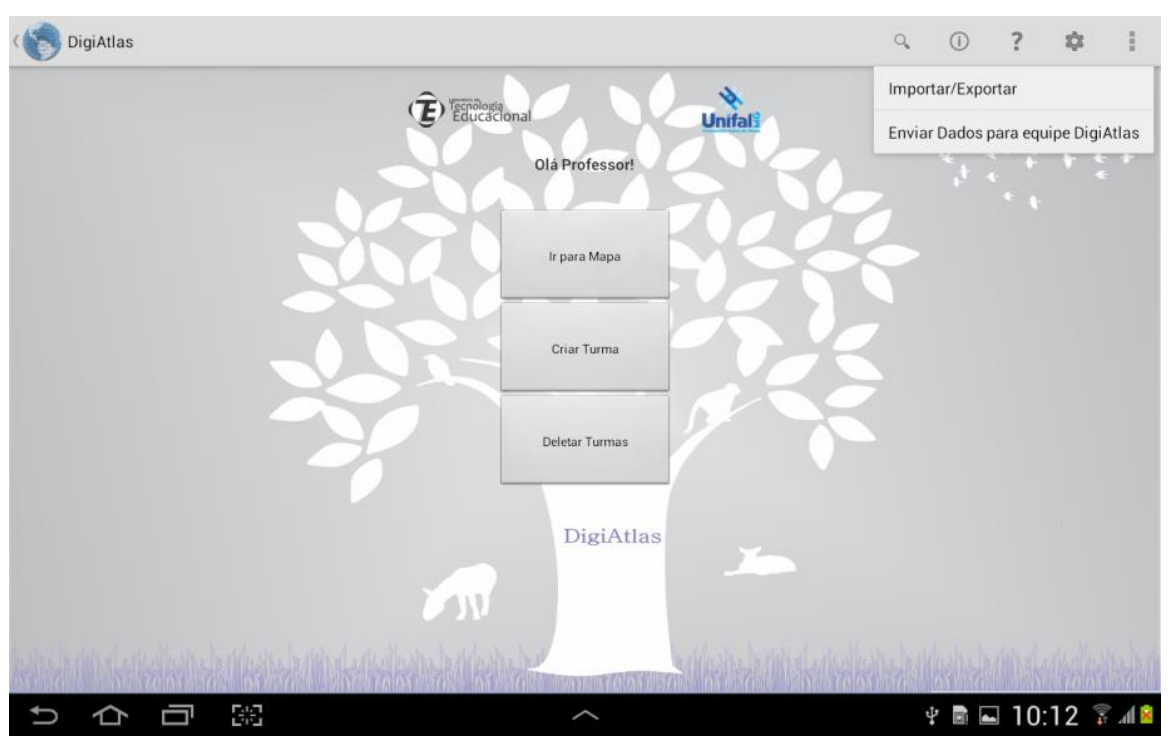

Figura 1. Tela secundária do DigiAtlas.

A aplicação permite a exportação de dados não-validados como forma de compartilhamento entre usuários do aplicativo ou como backup. O compartilhamento acontece com a importação desses dados. Ao realizar a exportação, uma pasta é criada contendo um arquivo de registro dos dados exportados, "export.da", junto com as mídias de cada dado. Na importação, além do arquivo "export.da" ser lido, será necessário informar a fonte dos dados, o que permite a exclusão dos dados de uma fonte específica sem interferir em dados importados de outras fontes.

Oportunamente os dados importados serão encaminhados aos pesquisadores em Ecologia da UNIFAL-MG, que serão avaliados e possivelmente validados. Esses dados ficarão disponíveis em atualizações do DigiAtlas, assim, este processo permitirá aos usuários colaborar com o projeto aumentando o tamanho da base de dados de forma coerente e controlada por pesquisadores da área.

$\mathrm{Na}$ estruturação da base de dados, cada dado foi classificado de acordo com seis tipos existentes na aplicação: Aves, Mamíferos, Invertebrados, Anfíbios, Plantas e Abióticos (que envolvem problemas ambientais e físicos). Isso implica que ao adicionar/editar um dado o usuário deve especificar o tipo do dado restringindo a um dos citados anteriormente, com isso tem-se uma melhor organização dos dados no DigiAtlas. Para uma melhor interação com os marcadores, foram utilizados ícones para a representação de um tema, os quais possuem desenhos diferentes relativos aos tipos existentes na localidade. Por exemplo, se em uma localidade somente existir mamíferos cadastrados, somente o desenho do "macaco" aparecerá no marcador. Dessa forma o usuário consegue saber antecipadamente quais os tipos de dados que ele pode encontrar no marcador (Figura 2.a). 


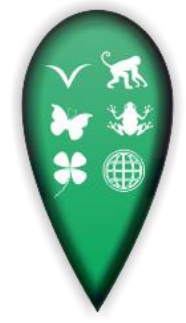

a)

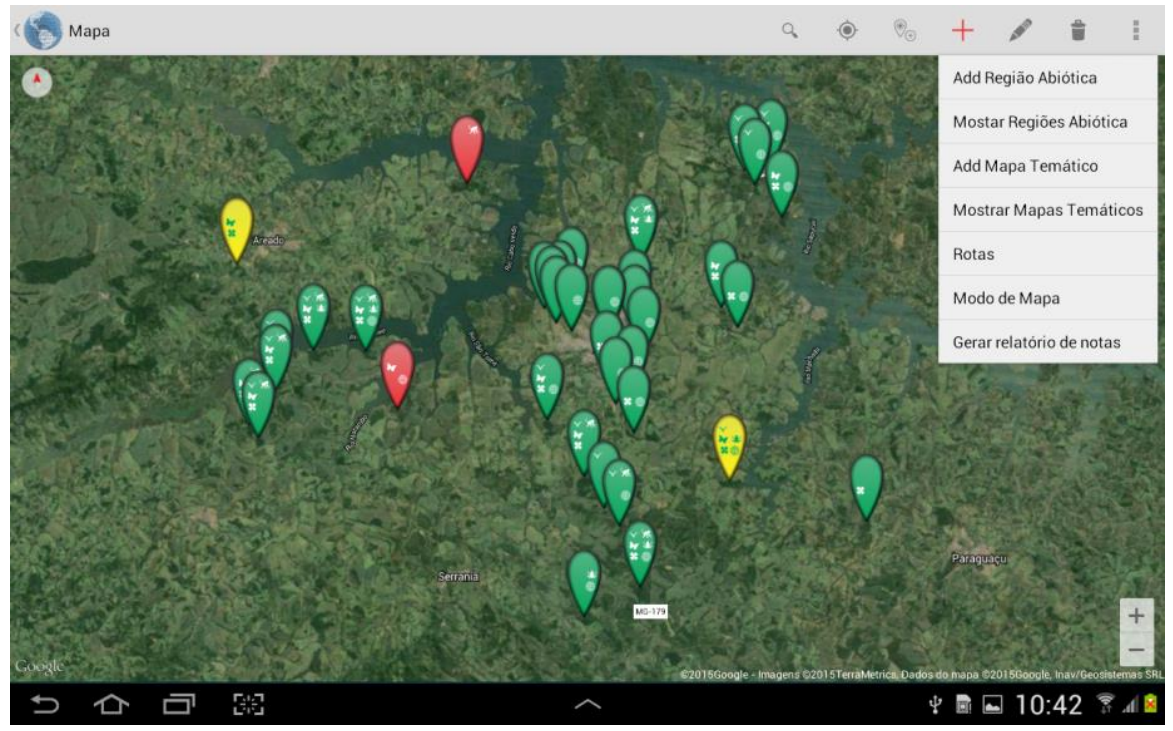

b)

Figura 2. a) Marcador com ícones dos seis tipos. b) Mapa com diversos marcadores e a opção Adição ativada.

No mapa integrado (Figura 2.b), também no canto direito da barra superior, existem as opções: Pesquisa, Localização, Adição de Marcador na Localização, Adição, Edição e Exclusão de dados, Adição de Região Abiótica, Exibir/Ocultar Região Abiótica, Adição de Mapa Temático, Exibir/Ocultar Mapa Temático, Rotas, Modo de Mapa (já disponível pelo Google Maps) e Gerar relatório de notas.

Quando selecionada a operação de Adição, é possível adicionar novos dados em marcadores existentes ou ainda adicionar um novo marcador, e em seguida adicionar o novo dado nesse marcador. As operações de edição e exclusão podem ser realizadas somente sobre dados não-validados. A adição de uma região abiótica é a delimitação de determinada área cuja informação é relevante para o estudo, por exemplo, uma área de preservação ambiental. A Figura 3.a é um exemplo de região abiótica.
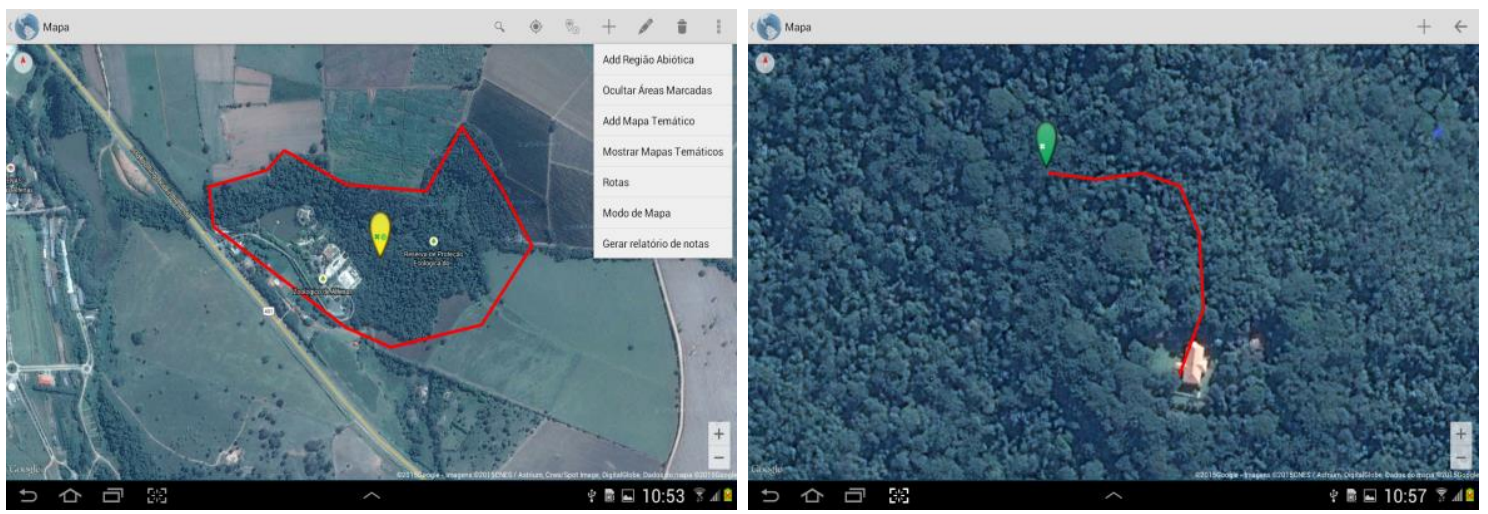

Figura 3. a) Região Abiótica. b) Rota.

Quando a Localização é solicitada pelo usuário, o campo de visão no mapa é deslocado e um círculo vermelho surge no mapa assim que forem encontradas as coordenadas do aparelho. Mapas temáticos são imagens sobrepostas no mapa que 


\section{CBIE-LACLO 2015}

Anais dos Workshops do IV Congresso Brasileiro de Informática na Educação (CBIE 2015)

contem informações, como a temperatura da região em um determinado ano, ou uma representação do solo dessa região, ou ainda qualquer informação relevante que vem a acrescentar conhecimento ao usuário. As Rotas, como mostrado na Figura 3.b, são caminhos definidos pelo próprio usuário e são criadas com o intuito de auxiliar em pesquisas no campo para mostrar ao usuário como chegar ao local desejado. Já a opção de gerar relatório de notas exibe todas as anotações com sua respectiva localidade.

Após a seleção de um marcador (Figura 4) a janela de informações mostra a localização (Latitude/Longitude), as imagens nítidas representam os dados existentes nessa localidade, e as imagens acinzentadas representam dados inexistentes. Também é nesse momento que as anotações são visualizadas individualmente, sendo possível adicionar/editar a anotação sobre essa localidade.

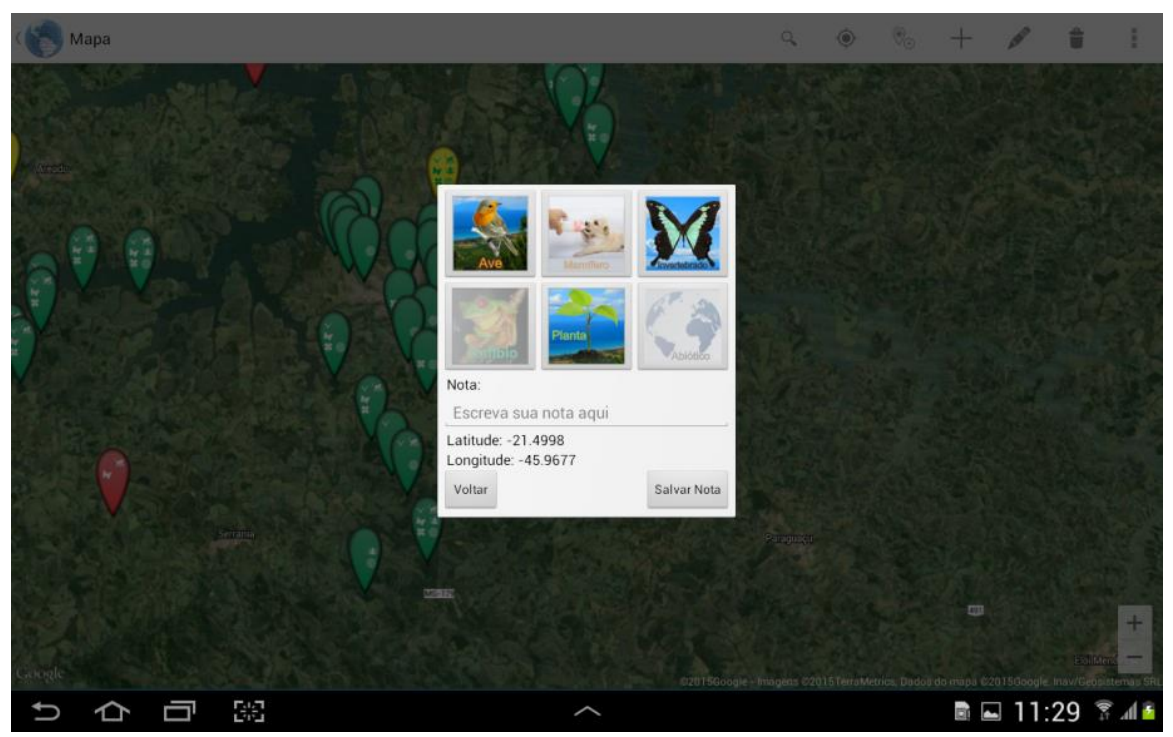

Figura 4. Janela de Informações.

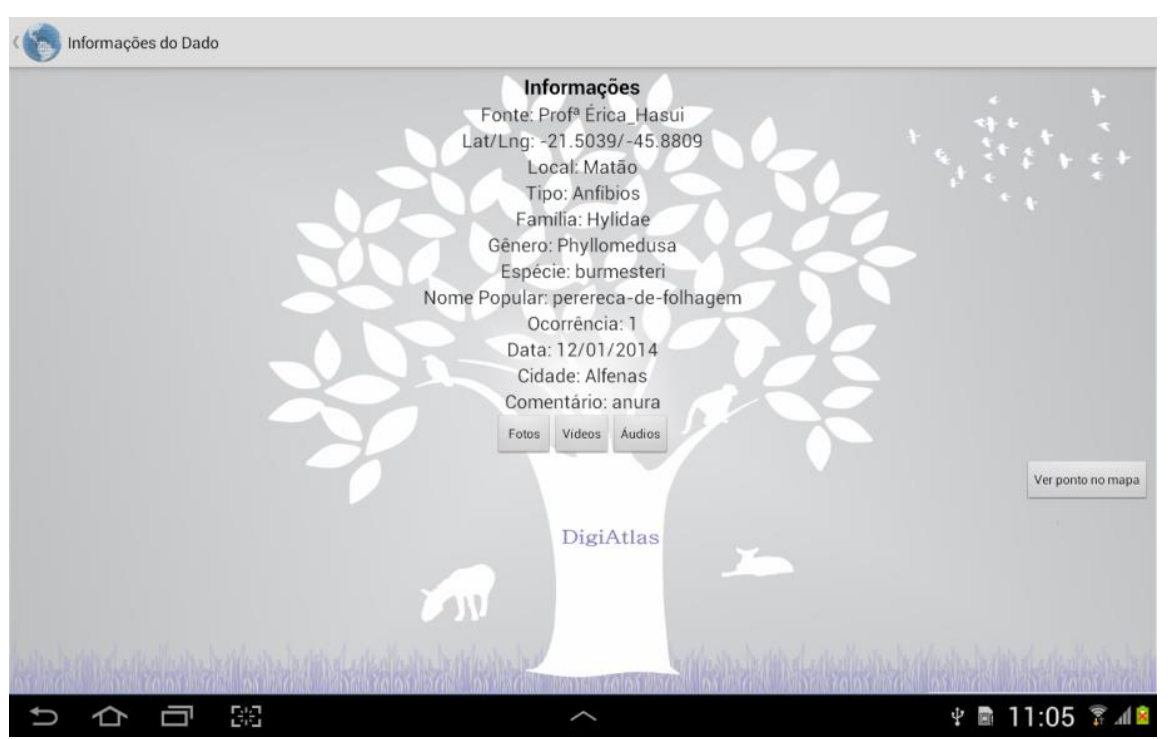

Figura 5. Informações de um Dado.

As informações de um dado (Figura 5) que foi pesquisado ou descoberto no mapa possuem atributos intuitivos, sendo que um dado não necessariamente possui 
todos atributos. Os atributos são: Fonte que coletou e disponibilizou o dado; Latitude/Longitude que especifica a localização; Local em que foi realizada a coleta; Tipo de dado (Aves, Mamíferos, Invertebrados, Anfíbios, Plantas e Abióticos); Família, Gênero e Espécie; Nome Popular (se existir); Ocorrência especificando o número indivíduos visualizados no local; Data da coleta; Cidade em que foi realizada a coleta; Comentário ou alguma informação extra sobre o dado.

A partir das informações do dado é possível visualizar no mapa a localização desse dado, assim como também ir para as galerias de áudio, fotos e vídeos. Nas galerias são apresentadas as mídias existentes do dado ou pode-se adicionar novas mídias utilizando-se dos próprios recursos do aparelho (câmera e microfone).

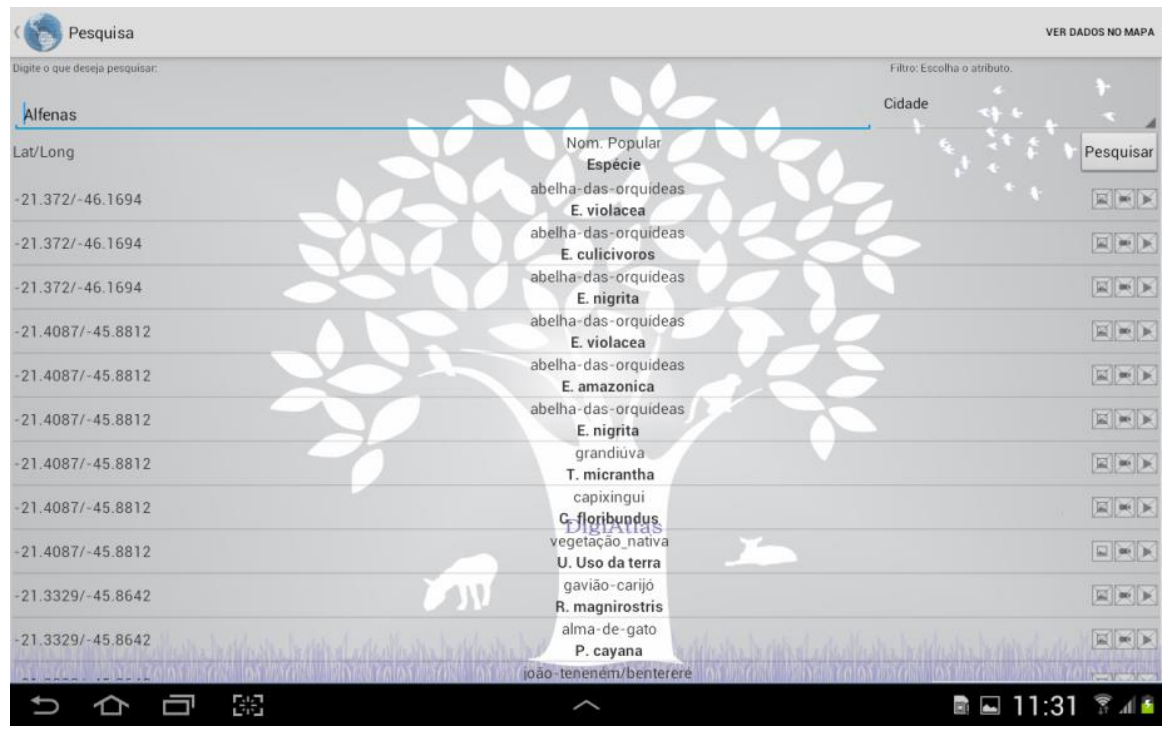

Figura 6. Resultado de uma pesquisa.

A operação Pesquisa pode ser acessada tanto logo após se autentificar ou a partir do mapa no ícone de uma lupa na barra no canto superior direito. Inicialmente a busca é realizada em toda base de dados, em todos atributos. Se houver uma ocorrência do que foi especificado pelo usuário em algum atributo de um dado, este é colocado na lista. Após o resultado apresentado existe a possibilidade de filtragem de acordo com um atributo desejado, o que permite diminuir a quantidade de resultados apresentados. Feita uma pesquisa, é possível visualizar no mapa somente os marcadores dos dados que foram resultados da pesquisa. Caso o dado tenha uma mídia, isto será indicado pelos ícones ao final da linha, conforme mostra a Figura 6.

\section{Análise de resultados: Avaliação de usabilidade}

Como análise de resultados foi utilizada a avaliação de usabilidade, seguindo os princípios apresentados por Nielsen e Budiu [2014]. Essa avaliação é essencial para a validação do DigiAtlas como ferramenta de ensino. Se o software for complexo, desestimula quem o utiliza, interferindo diretamente assim na aprendizagem.

Usabilidade de acordo com a ISO 9241 é "uma medida na qual um produto pode ser usado por usuários específicos para alcançar objetivos específicos com eficácia, eficiência e satisfação em um contexto específico de uso", ou seja, o aplicativo deve 
fornecer uma fácil interação com o usuário, onde este esteja à vontade para realizar as tarefas que o aplicativo se propõe, e as realize sem dificuldades.

O teste foi realizado na forma qualitativa e não estatística, pois segundo Nielsen e Budiu [2014], esse tipo de pesquisa é mais bem realizada nessa forma. Após enxergar uma dificuldade em determinada ação para um usuário e concluir que ela também será para a maioria dos demais usuários, você procura sanar essa dificuldade, e não verificar a porcentagem exata de usuários que tiveram a mesma dificuldade, por exemplo se foi de $63 \%$ ou $66 \%$. Foi utilizado o método cognitivo, um método de inspeção de usabilidade que tem como princípio avaliar a facilidade de aprendizagem de uma interface computacional [Lews \& Wharton, 1997]. Esse método baseia-se na teoria de aprendizagem por exploração, pois estudos demonstram que os usuários preferem aprender como usar sistemas explorando suas funcionalidades, e não através de treinamento ou consultas a manuais [Dix et al., 2004][Lews \& Wharton, 1997].

Em avaliações de usabilidade, um pequeno número de usuários já traz resultados bastante satisfatórios, por isso foram escolhidos três professores do projeto para participarem da avaliação, que foi realizada individualmente com cerca de 20 minutos de duração por pessoa. O aparelho foi comum a todos, um tablet 'Sansumg Galaxy Note 10.1', como também o roteiro de ações a serem realizadas. Para cada ação foi questionado o nível de dificuldade que o usuário teve ao tentar realizar a ação. Os níveis de dificuldade eram cinco, sendo eles: 'muito fácil', 'fácil', 'intermediário', 'difícil' e 'muito difícil'.

O roteiro de ações propostas e executadas é apresentado na coluna da esquerda na Tabela 1. Nas demais colunas são apresentadas as dificuldades consideradas por professor.

Tabela 1. Nível de dificuldade referente a cada ação e professor.

\begin{tabular}{|c|c|c|c|}
\hline Ação & Prof 1 & Prof 2 & Prof 3 \\
\hline 1- Crie uma turma. & Muito fácil & Muito fácil & Muito fácil \\
\hline $\begin{array}{l}\text { 2.1- Através da ferramenta pesquisa (lupa), } \\
\text { encontre as localidades ( } 3 \text { ) que a espécie } \\
\text { Cariama cristata (C. cristata ou seriema) ocorre. }\end{array}$ & Fácil & Intermediário & Muito fácil \\
\hline 2.2- Abra a imagem e o áudio da espécie. & Fácil & Fácil & Muito fácil \\
\hline 3.1- Crie um marcador para essa nova localidade. & Intermediário & Muito fácil & Intermediário \\
\hline 3.2- Adicione o novo dado nesse marcador & Fácil & Muito fácil & Fácil \\
\hline $\begin{array}{l}\text { 3.3- Edite a data e ocorrência do dado adicionado } \\
\text { e faça logout. }\end{array}$ & Muito fácil & Intermediário & Fácil \\
\hline
\end{tabular}

Como podemos ver apenas a ação de 'Criar um marcador para essa nova localidade' foi considerada com o nível de dificuldade intermediário por mais de um professor. Mesmo assim algumas sugestões foram feitas visto que a priori o usuário se sentia induzido a realizar tarefas de uma forma diferente, mas logo descobria a forma proposta pelo DigiAtlas. Um exemplo disso são os ícones que demostram quais mídias um certo dado possui, como vimos na Figura 6. Os usuários tentaram acessar a galeria de imagem e áudio ao clicar nos ícones correspondentes, contudo foram direcionados para a tela de informação do dado, e em seguida conseguiram acesso a cada uma das galerias. 
Dois dos três professores confundiram o ícone de "Adição de Marcador na Localização", que o próprio nome nos diz sua funcionalidade, com o ícone de "Adição", que funciona tanto para como adicionar marcador com o toque longo no mapa como também adicionar um dado num marcador com o toque no marcador desejado.

Após seguirem o roteiro os professores ficaram à vontade utilizar o aplicativo, elogios foram feitos quanto a iconografia relacionando os tipos existentes em um marcador e também a possibilidade de Importação/Exportação. Dois dos três professores removeram o dado adicionado sem dificuldade, contudo um deles sugeriu a união da edição com a remoção, o que reduziria o número de ícones na barra superior e para ele seria mais intuitivo.

Através do teste buscamos verificar a usabilidade das operações chaves do DigiAtlas. Como resultado podemos observar que são pequenos os ajustes que podem ser feitos a fim de melhorar a experiência de uso do DigiAtlas, sendo que os usuários conseguiram realizar sem dificuldades ações do roteiro e também se sentiram à vontade para realizar algumas que não foram requisitadas.

\section{Considerações Finais e Trabalhos Futuros}

Neste trabalho foram apresentados os motivos para a produção de uma aplicação de ensino-aprendizagem para dispositivos móveis, como também os resultados da implementação de uma aplicação móvel, o DigiAtlas, que permite a manipulação de dados ambientais com o intuito de compartilhamento e disseminação do conhecimento.

Até o momento foram implementadas várias funcionalidades para a manipulação de dados no DigiAtlas, as quais foram analisadas aplicando um teste de usabilidade com alguns professores envolvidos no projeto. Tal análise traz um resultado satisfatório de facilidade de uso da aplicação, e assim, pode-se considerar que existe pouca complexidade de uso que poderia atrapalhar no ensino-aprendizado. Outras funcionalidades como Localização e Adição de Rotas podem auxiliar o trabalho de campo em uma aula, ou de um pesquisador coletando dados.

Futuramente em uma análise mais específica, o DigiAtlas passará por testes com alunos do ensino fundamental, médio e graduação, para experiência em uma atividade prática. Além disso, outras funcionalidades serão desenvolvidas como a comunicação com um servidor, que fará com que novos dados validados sejam sincronizados automaticamente com os dispositivos que possuírem a aplicação.

\section{Agradecimento}

A FAPEMIG (Fundação de Amparo à Pesquisa do Estado de Minas Gerais) pelo apoio financeiro ao projeto.

\section{Referências}

Associação Brasileira de Normas Técnicas (1998). ISO 9241-11 - Requisitos ergonômicos para o trabalho com dispositivos de interação visual. Parte 11: Orientações sobre usabilidade.

CRARY, J. (1999). Suspensions of perception (attention, spectacle, and modern culture). Cambridge, MA: MIT Press. 
Distimo (2013), “The Mobile App Ecosystem: Global trends in established and growth markets", http://www.distimo.com/download/publication/Distimo_Publication_MEF_Mobile_ App_Ecosystem___September_2013/EN/archive, 14 de Maio de 2015.

Dix, A., Finlay, J., Abowd, G., \& Beale, R. (2004). Human-Computer Interaction. Prentice-Hall International, $4^{\text {th }}$ edition.

Duso, L., \& Borges, R. M. R. (2010). Mudança de Atitude de Estudantes do Ensino Médio a Partir de Um Projeto Interdisciplinar Sobre Temática Ambiental. Alexandria Revista de Educação Em Ciência E Tecnologia, p. 51-76.

Ferreira, E., \& Tomé, I. (2010). Jovens, Telemóveis e Escola. Educação, Formação \& Tecnologias, p. 24-34.

Fundação SOS Mata Atlântica, Instituto Nacional de Pesquisas Espaciais (2014) "Atlas dos remanescentes florestais da Mata Atlântica Período 2012-2013”. São Paulo, p 61.

Lewis, C. \& Wharton, C. (1997). Handbook of human-computer interaction, chapter 30Cognitive Walkthroughs, 717-730. Elsevier Science B. V., $2^{\text {nd }}$ edition.

Nielsen, J., \& Budiu, R. (2014). Usabilidade Móvel. Elsevier Editora Ltda.

Pinto, M.L.C. (2003) Trabalho de Campo e o processo de aprendizagem em busca de um método. Espaços da Escola, $\mathrm{O}$ ensino da geografia na educação básica. Ijuí: UNIJUÍ, Ano 12, n. 47, p. 15-20.

Sharples, M., Taylor, J., \& Vavoula, G. (2007). A Theory of Learning for the Mobile Age. In R. Andrews \& C. Haythornthwaite (Eds.), The Sage Handbook of Elearning Research, pages 221-47. London: Sage. 